\title{
Desafiando a interdisciplinaridade na ciência administrativa: o caso da entropia
}

\section{Challenging interdisciplinarity in the administrative science: the case of Entropy}

\author{
Uajará Pessoa Araújo ${ }^{1}$ \\ Centro Federal de Educação Tecnológica de Minas Gerais (CEFET-MG) / Departamento de Ciências Sociais Aplicadas, Belo \\ Horizonte - MG, Brasil \\ Paulo Fernandes Sanches Júnior² \\ Centro Federal de Educação Tecnológica de Minas Gerais (CEFET-MG) / Departamento de Ciências Sociais Aplicadas, Belo \\ Horizonte - MG, Brasil \\ Almiralva Ferraz Gomes ${ }^{3}$ \\ Universidade Estadual do Sudoeste da Bahia (UESB) / Departamento de Ciências Sociais Aplicadas, Vitória da Conquista - BA, \\ Brasil
}

\begin{abstract}
Resumo
O estímulo da ciência e da educação aos esforços interdisciplinares remonta a décadas. Parece que o movimento ganhou impulso e, nessa dinâmica, é cada vez mais provável ser exposto a um discurso que apresenta as vantagens da interdisciplinaridade e é omisso quanto aos seus riscos. Colocar a interdisciplinaridade em teste foi uma das motivações deste ensaio qualitativo e descritivo, que lidou com dados empíricos de natureza bibliográfica e documental, complementados por entrevistas. O objetivo estratégico foi investigar a compreensão na ciência administrativa da grandeza entropia, presente na Teoria Geral dos Sistemas (TGS), que é tida como proposição interdisciplinar de impacto atual, sessenta anos depois de sua apresentação. Concluiu-se que a Administração tem problemas ao trabalhar com essa grandeza, pois, enquanto o conhecimento gerado pela aplicação instrumental da interpretação estatística da entropia percebeu-se sólido, as interpretações de caráter termodinâmico da entropia são passíveis de contestação, que foram ignoradas ao longo do período, com implicações negativas e substanciais, uma vez que a entropia não explica a desordem organizacional, como foi incorporado pela Administração. Isso, ainda que não provado, deve estar ligado à inabilidade de lidar com conceitos e leis fundamentais importados de outras disciplinas, o que, extrapolando, deve ser suficiente para relativizar a combinação de saberes entre campos de conhecimento: há riscos da interdisciplinaridade produzir e reproduzir erros.
\end{abstract}

Palavras-chave: Interdisciplinaridade. Entropia. Teoria Geral dos Sistemas.

Artigo recebido em 15 de agosto de 2014 e aceito para publicação em 11 de junho de 2015.

\section{DOI: http://dx.doi.org/10.1590/1679-395131772}

${ }^{1}$ Doutor em Administração pela Universidade Federal de Lavras (UFLA) e em Engenharia da Produção pela Universidade de São Paulo (USP); Professor adjunto do Departamento de Ciências Sociais Aplicadas do CEFET-MG. Endereço: Av. Amazonas, 7675, prédio principal - sala 203 - Nova Gameleira, CEP 30510-000, Belo Horizonte - MG, Brasil. E-mail: uajara@dcsa.cefetmg.br

2 Doutor em Engenharia Civil pela Universidade Estadual de Campinas (UNICAMP); Professor adjunto do Departamento de Ciências Sociais Aplicadas do CEFET-MG. Endereço: Av. Amazonas, 7675, prédio principal - sala 203 - Nova Gameleira, CEP 30510-000, Belo Horizonte - MG, Brasil. E-mail: sanches@dcsa.cefetmg.br

${ }^{3}$ Doutora em Administração pela Universidade Federal de Lavras (UFLA); Professora do Departamento de Ciências Sociais Aplicadas da UESB. Endereço: Estrada do Bem Querer, km 4, UESB, CEP 45083-900, Vitória da Conquista - BA, Brasil. E-mail: almiralva@gmail.com 


\begin{abstract}
The stimulus of science and education to interdisciplinary efforts dates back decades. It seems that the movement has gained momentum and, in this dynamic, it is increasingly likely to be exposed to a discourse that has the advantages of interdisciplinarity and says nothing about its risks. Putting interdisciplinarity at stake was among the motivations for this qualitative and descriptive essay, which dealt with empirical data having a bibliographic and documentary nature, supplemented by interviews. The strategic objective was investigating people's understanding within administrative science on the magnitude entropy, observed in the General Systems Theory (GST), which is seen as an interdisciplinary proposition with a current impact, sixty years after its introduction. It was concluded that Administration faces problems when working with this magnitude, because, while knowledge generated through the instrumental application of statistical interpretation of entropy realized itself as concrete, interpretations on entropy having a thermodynamic nature are likely to dispute, and they were ignored within the period, with negative and substantial implications, since entropy does not explain organizational disorder, such as embodied by Administration. This, though not proven, must be linked to the inability to deal with key concepts and laws imported from other disciplines, which, extrapolating, should be enough to make relative the combination of knowledge between knowledge fields: there are risks that interdisciplinarity produce and reproduce mistakes.
\end{abstract}

Keywords: Interdisciplinarity. Entropy. General Systems Theory.

\title{
Introdução
}

Este ensaio lidou com a entropia, de acordo com o ensinado em livros-texto da Administração e apropriado para a explicação de fenômenos organizacionais, com o fito de discutir a questão da interdisciplinaridade na área.

A entropia é uma grandeza que faz parte do currículo do segundo grau (SÃO PAULO, 2010), quando associada à Segunda Lei da Termodinâmica, inquestionável e universal. O conceito é (ou pode ser) retomado na graduação quando se introduz a Teoria Geral dos Sistemas (TGS) e, com ela, outras propriedades dos sistemas, como equifinalidade e homeostase - compondo uma explicação interdisciplinar (biológica e termodinâmica) para a tendência das coisas, no geral, e das organizações, em especial, caminharem naturalmente para a desordem, para a disfuncionalidade. O conceito, já familiar da educação básica é repaginado e agora pode dar sentido a: (1) as organizações tendem a deteriorar-se; (2) a entropia está associada à deterioração; (3) deve-se combater a entropia para preservar a funcionalidade das organizações. Uma dedução simples, aceitável, determinista e relevante ao induzir um estado permanente de alerta diante de um condicionamento da física aplicável às entidades organizacionais, aparentemente comprovado pela observação e na prática - o que aqui será examinada mais profundamente como campo de teste para a interdisciplinaridade.

A incursão de saberes originários de outros campos científicos na Administração - por definição, uma aplicação da sociologia - não se limita à termodinâmica e à Biologia. Teorias e instrumentos da pesquisa operacional, da ergonomia, da Psicologia, da psicanálise, da Economia e de outras áreas dão sustentação ao arcabouço da administração moderna, desde seus primórdios. Ainda, tal como proposto por Aboni, Andrade, Lima et al. (2012), aceita-se que gestores, docentes e alunos lidem melhor com a complexidade contemporânea adotando uma estratégia de entendimento interdisciplinar, capaz de produzir uma mediação possível entre saberes e competências e de instigar, pela prática, a curiosidade epistemológica.

Entretanto, a interdisciplinaridade não é infensa a riscos. Tal assertiva pode ser encaminhada adotando como estratégia descrever, analisar e entender de que modo o ensino e as pesquisas em Administração incorporaram o conceito de entropia, questão tomada como primária à pesquisa. Feito isso, o próximo passo é levar à reflexão sobre os riscos que podem estar associados à apropriação de conceitos exógenos, sem cuidados redobrados - constituindo-se, assim, no objetivo último e no qual se assenta a relevância desta investigação, que se desdobrou nas seções seguintes à essa introdução: fundamentação - reservada a uma breve revisão sobre a interdisciplinaridade e a entropia; método da investigação; e resultados, onde foi 
considerado mais conveniente empregar a forma de um texto discursivo, subsidiando a conclusão, ao final deste ensaio.

\section{Fundamentação}

\section{Interdisciplinaridade}

A conceituação sobre a interdisciplinaridade e sua relação com o ensino e a pesquisa da Administração, mantida neste ensaio, foi somente uma conceituação básica, uma vez que já estão disponíveis textos, mesmo nacionais, como o trabalho de Aboni, Andrade, Lima et al. (2012), que abordam com profundidade a interdisciplinaridade, contextualizando-a na Administração.

Como de praxe em trabalhos da área, há a necessidade inicial de se estabelecer como lidar com as ambiguidades (diferenças e semelhanças) ligadas à estratégia de aplicação de duas a mais disciplinas sobre um problema científico. O recurso é combinar dois eixos: no primeiro, o grau de baixo, moderado e alto nível de interconectividade, de integração intelectual. No outro, o escopo da integração, que pode variar entre formas horizontais de integração de disciplinas vizinhas com epistemologia compatíveis; e formas mais verticalizadas, de disciplinas com epistemologias divergentes (KLEIN, 2008). Daí, é recorrente encontrar a multidisciplinaridade como mera justaposição de diversas perspectivas. Já a pesquisa interdisciplinar (PID) demandaria uma integração propriamente dita. Por fim, a transdisciplinaridade como processo no qual membros de diferentes campos trabalham juntos durante um período de tempo considerável para desenvolver novas estruturas conceituais e metodológicas com o fito de produzir perspectivas teóricas que transcendem às originais (JACOBS e FRICKEL, 2009; KLEIN, 2008) - salientando que os três modelos cabem nos quadrantes horizontal ou vertical.

Posto isso e considerando a complexidade da ciência, Klein (2008) adverte que não se tratam de hierarquias mutuamente exclusivas. Barry, Born e Weszkalnys (2008) e Jacobs e Frickel (2009), por sua vez, preferem generalizar tudo como interdisciplinar, no que foi secundado pelos autores deste ensaio, que adotaram uma definição: a PID consiste em um modo de investigação pelo qual um indivíduo ou equipes integram informação, técnicas, perspectivas, e/ou teorias de duas ou mais disciplinas com o objetivo de compreender melhor os fundamentos ou resolver problemas cuja solução está além do escopo de uma única disciplina (NATIONAL ACADEMY OF SCIENCES, 2005).

Nas palavras de Klein (2008, p. 116), e de Porter e Rafols (2009, p. 719), a interdisciplinaridade vem tornando-se um "mantra" ou "o jeito certo", como indicado por uma pesquisa em universidades americanas que revelou que $70 \%$ dos entrevistados concordam fortemente com a afirmação: "conhecimento interdisciplinar é melhor que conhecimento obtido de uma única disciplina" (JACOBS e FRICKEL, 2009, p. 46). Apenas engenheiros mecânicos e economistas tenderam a discordar. Entre os sociólogos, a PID seria laureada como ideal, esconjurada como ameaça e abraçada como prática (JACOBS e FRICKEL, 2009).

Ano após ano publicam-se mais artigos que de alguma forma aplicam a interdisciplinaridade (JACOBS e FRICKEL, 2009), mesmo que esse crescimento não seja tão acelerado quanto se possa imaginar e que a interdisciplinaridade horizontal seja dominante (PORTER e RAFOLS, 2009). Em parte, a proeminência da interdisciplinaridade resulta dos esforços deliberados das universidades e das agências de fomento, como aqueles reportados por Jacobs e Frickel (2009) e mesmo de políticas governamentais, quando se acredita que a PID é capaz de forjar relações mais estreitas entre ciência e tecnologia (BARRY, BORN e WESZKALNYS, 2008).

Adicionadas a isso, estão as necessidades do setor privado de solução de problemas complexos, não contidos no conhecimento de uma única disciplina. É um volume significativo de recursos financeiros e humanos, 
envolvidos na promoção de iniciativas interdisciplinares. Por outo lado, conforme atrai praticantes, a PID acaba tornando-se objeto de investigações ligadas ao seu ensino, às suas práticas, à sua epistemologia e à sua construção teórica, histórica, política e econômica. Periódicos com ênfase em ciência da informação (MORILLO, BORDONS e GÓMEZ, 2003), meio ambiente (PERZ et al., 2010), saúde (ABOELELA, ABOELELA e LARSON, 2007; KLEIN, 2008), Ciências Sociais (BARRY, BORN e WESZKALNYS et al., 2008; HUUTONIEMI, KLEIN, BRUUN et al., 2010; PORTER e RAFOLS, 2009; RIJNSOEVER e HESSELS, 2011) e Educação (BORREGO e NEWSWANDER, 2010) debruçaram-se sobre o tema.

Excetuando alguns poucos trabalhos, como o de Barry, Born e Weszkalnys et al. (2008), absorve-se do conjunto de literatura examinada um discurso acrítico que apresenta a PID como heterogênea, aberta e contemporânea, em oposição à convencionalidade e padronização artificial impeditiva de novas perspectivas que caracterizariam o esforço (uni)disciplinar.

\section{Entropia e interdisciplinaridade}

Com esse cenário, a atenção volta ao segundo conceito, a entropia, que remete inicialmente à termodinâmica. Com o tempo, ela foi apropriada por outros campos do conhecimento e hoje é encontrada em textos de Biologia, de ecologia e em Ciências Sociais. É comum associar entropia à imprevisibilidade, à casualidade, ao caos ou à complexidade (MARTIN, SMITH e FRANCIS, 2013; MAVROFIDES, KAMEAS, PAPAGEORGIOU et al., 2011). É também recorrente encontrá-la como degradação ou morte do sistema (KATZ e KAHN, 1987).

Como já apresentado, a Administração teve contato com a entropia por meio da TGS, desenvolvida em 1947 por Ludwig von Bertalanffy, que a concebeu como um esforço interdisciplinar, apropriando-se de conhecimentos da termodinâmica, da estatística e da Biologia, para o entendimento de vários fenômenos, inclusive os sociais, empregando os organismos vivos como modelo (BAILEY, 2001; MORGAN, 2007).

A adoção dos elementos, dos métodos analíticos e da perspectiva da TGS seria útil e cada vez mais frequente (BYEON, 2005), ainda que enfrente algumas restrições (BAILEY, 2001). Entre os elementos da TGS, a entropia destaca-se por estar associada a situações de não equilíbrio e à necessidade de novos padrões e estruturas (BYEON, 2005; MAVROFIDES, KAMEAS, PAPAGEORGIOU et al., 2011).

Mas é difícil ter uma compreensão clara do conceito de entropia (BENGUIGUI, 2013; MARTIN et al., 2013; SCHRÖDINGER, 1944). Mesmo os especialistas em Física chegam a confessar que não existe uma boa resposta para a questão sobre o que é essa grandeza (ÇENGEL e BOLES, 2011). Se é assim para eles, imagine para os leigos. Para estes, a entropia é um termo abstrato, obscuro e negativo, que os obriga a uma reverência, dada a conexão da entropia com a termodinâmica, considerando-a uma força perversa que levará a raça humana ao perecimento devido à degradação da energia do universo (CORNING e KLINE, 1998).

Bailey (2001) exemplifica e chama a atenção para o entendimento errôneo e o uso inapropriado de conceitos da Física, mormente da entropia, em Ciências Sociais, impondo-se como um importante assunto acadêmico à medida que são valorizados os esforços interdisciplinares. Para Bailey (2001), referendado por Byeon (2005), a apropriação inadequada de conceitos de outra disciplina gera falta de clareza, aumento de ambiguidade, mudança de significado e perda de informação. Com isso, se é inviável replicar o uso do conceito original, pelo menos deveriam ser transportadas as propriedades originais para o conceito análogo, distinguindo-os via adjetivação, se for o caso (entropia termodinâmica, de Clausius; entropia estatística, de Boltzmann; entropia da informação, de Shannon; entropia social, de Bailey). Com isso, o conceito passou a cobrir uma coleção de ideias correlatas, porém, distintas (FISK, 2011, p. 1936).

Daí, conclui-se que é necessário explorar mais detalhadamente as definições de entropia, resultantes das propostas originais de Clausius, em 1864, portanto, há 150 anos e de Boltzmann, em 1877 (BENGUIGUI, 2013). De acordo com a perspectiva termodinâmica, haveria duas conceituações de entropia. Uma terceira, a entropia da informação, recebe respaldo de outra ciência, a da comunicação. Na termodinâmica, a entropia 
aparece: (i) diretamente relacionada à degradação de energia na conversão de calor em energia mecânica; e (ii) indiretamente, às probabilidades de determinação da disposição e da trajetória de moléculas em um sistema submetido aos condicionantes termodinâmicos - portanto, incerteza e não desordem. $\mathrm{O}$ terceiro sentido deriva do segundo e mede a probabilidade de um símbolo específico aparecer na sequência de uma mensagem (MAVROFIDES, KAMEAS, PAPAGEORGIOU et al., 2011).

\section{Entropia na termodinâmica}

A entropia está ligada à degradação, mas somente de energia. Quando se realiza trabalho, a quantidade de energia empregada é maior que o trabalho realizado por uma fração correspondente à energia transformada em calor de baixa temperatura, incapaz de ser recuperado (ÇENGEL e BOLES, 2011; MARTIN SMITH e FRANCIS, 2013; SCHMIDT, HENDERSON e WOLGEMUTH, 2004; SONNTAG, BORGNAKKE e WILEN, 2003). Essa constatação é o ponto de partida da termodinâmica, que permite diferenciar processos reversíveis e irreversíveis, por meio da entropia (S). A termodinâmica estabelece que se há alguma transformação, a entropia do universo permanece constante (processos reversíveis) ou aumenta (processos irreversíveis), quando se pode dizer que há produção de entropia (PRIGOGINE, 1977).

Uma boa aproximação da entropia é considerá-la como medida do grau de aleatoriedade das moléculas de um Sistema. Mesmo no sólido, as moléculas não estão paradas, oscilando diante de suas posições de equilíbrio. Contudo, nesta fase, uma molécula não pode mover-se em relação às outras e, assim, sua posição pode ser referida com alguma certeza. Essa certeza é bem menor em líquido e muito menor na fase gasosa, quando a molécula pode mover-se aleatoriamente, colidir com outra e mudar de direção, tornando muito difícil prever o estado microscópico do Sistema em análise. Assim, a entropia cresce quando uma substância passa de sólido para o líquido e de líquido para a fase gasosa. A movimentação é proporcional à temperatura, de tal forma que, em temperaturas extremamente baixas, as moléculas, teoricamente, ficariam paradas - o que corresponde à entropia zero, quando se saberia com precisão a posição de cada molécula (ÇENGEL e BOLES, 2011). À baixa temperatura, formam-se estruturas ordenadas (de menor entropia): dentro dessa estrutura, cada átomo ou molécula interage com seu vizinho e as energias cinéticas são tão pequenas que essas forças de interação mantêm as partículas praticamente imóveis. À alta temperatura, acontece a desordem molecular no estado líquido e ainda maior, no estado gasoso (PRIGOGINE e STENGERS, 1984).

É comum tentar explicar entropia considerando as múltiplas possibilidades de dispor livros em estantes, desde aquela com restrição máxima (alfabética, por autor e algum critério secundário), em que só cabe uma única disposição - entropia baixa - até aquela em que os livros são expostos de forma aleatória - entropia alta. Isso como analogia das múltiplas possibilidades de distribuir energia pelas moléculas para determinado conjunto de restrições termodinâmicas. Exemplo similar pode ser comparando um quarto arrumado (portanto, com poucas possibilidades de disposição de seus componentes), diante de outro, desarrumado, com uma multiplicidade muito maior (MARTIN, SMITH e FRANCIS, 2013).

Um ponto que mereceu destaque neste ensaio são algumas das propostas de Ilya R. Prigogine. Prigogine, prêmio Nobel em 1977, deu importante contribuição à termodinâmica de não equilíbrio aplicável a sistemas complexos e caóticos. Suas propostas teriam estimulado os físicos a dedicarem-se aos fenômenos distantes do equilíbrio como os problemas de auto-organização e de estruturas dissipativas. Prigogine trabalhou com o objetivo de conciliar a mecânica clássica (que estuda o movimento microscópico das partículas) com as variáveis macroscópicas, que são definidas pelo comportamento médio das variáveis microscópicas. Ele apresentou uma demonstração teórica na qual a evolução para o equilíbrio é mecânica e microscopicamente irreversível - tanto quanto no nível macroscópico (NOVAES, 2010).

Os argumentos de Prigogine partem do princípio que a entropia atinge seu máximo quando o sistema está em equilíbrio. Se, por alguma restrição, o equilíbrio não pode ser atingido, mas está próximo de ser atingido, o sistema se acomoda em um estado de menor dissipação, dito estado estacionário, de produção mínima de entropia (teorema da produção mínima de entropia). Se esse sistema é perturbado, a entropia aumenta, e o sistema reage, voltando à condição anterior. Daí, perto do equilíbrio, qualquer flutuação se esvaneceria. 
O equilíbrio traz uma resposta satisfatória no que diz respeito a um número imenso de fenômenos físicoquímicos (PRIGOGINE e STENGERS, 1991). Entretanto, não seria aplicável à natureza viva, à hidrodinâmica, à ciência dos fluxos e das turbulências, à meteorologia e à ciência da organização instável das massas de ar em função dos fluxos de matéria e calor (PRIGOGINE e STENGERS, 1991). Pois, quando o sistema está muito afastado do equilíbrio, ele se comporta de forma diferente, mesma oposta, ao teorema da produção mínima de entropia. É o caso de se aquecer um líquido por baixo. Primeiro, a transferência de calor se dá por condução (e o líquido permanece visivelmente parado). Em algum ponto, começa a convecção que produz um estado mais organizado que o anterior, pois um número macroscópico de moléculas tem de se mover de forma coerente (tomando a forma de células hexagonais de tamanho característico) durante algum tempo para que a convecção se estabeleça, ainda que macroscopicamente pareça que tenha havido aumento da desordem devido à turbulência. Esse é o exemplo de que o não equilíbrio pode ser fonte de ordem. Também ocorre em reações químicas dependendo da sua cinética (usualmente, com a presença de um catalisador). Um exemplo é o relógio químico: em condições distantes do equilíbrio, as moléculas mudam sua identidade química simultaneamente, a intervalos de tempos regulares, demonstrando a existência de uma nova ordem (PRIGOGINE e STENGERS, 1984).

De acordo com as propriedades da entropia estatística, a probabilidade dessas ocorrências seria quase zero, de tal forma que quando surge um estado novo e coerente (ordenado) em condições distantes do equilíbrio, o conceito de probabilidade dissipa-se. No caso da convecção, pode-se imaginar que, desde o começo do aquecimento e até um dado gradiente de temperatura, haveria pequenas convecções aparecendo como flutuações, mas essas flutuações não vão em frente e desaparecem (sem que isso seja perceptível). Entretanto, acima de um dado valor crítico, algumas flutuações são ampliadas dando origem à corrente macroscópica. Uma nova ordem supermolecular aparece correspondendo basicamente a uma enorme flutuação estabilizada pela troca de energia com o mundo exterior. Esta ordem caracteriza uma estrutura dissipativa (PRIGOGINE, 1977) e é resultante de um processo de auto-organização ou organização espontânea. Em tal processo, algumas flutuações locais, ao invés de retroagir, poderiam se expandir e invadir todo o sistema, compelindo-o a evoluir para uma situação que pode ser bem diferente daquele estado previsível pela termodinâmica do equilíbrio (PRIGOGINE e STENGERS, 1991).

Perto do equilíbrio, o comportamento do sistema é universal. Distante do equilíbrio, o comportamento tornase bem específico para cada sistema. As estruturas dissipativas são muito sensíveis às características do sistema e de sua fronteira. Por exemplo: a ocorrência de estrutura dissipativa requer que o tamanho do sistema seja maior que um valor crítico. Outra condição para se ter uma estrutura dissipativa são as trocas contínuas de matéria e energia entre o sistema e o meio. E mais, o tipo de estrutura dissipativa depende criticamente das condições (por exemplo: campo magnético e campo gravitacional) de sua formação, que tem papel significativo na seleção do mecanismo de auto-organização (PRIGOGINE e STENGERS, 1984).

Todos os sistemas contêm subsistemas que estão continuamente flutuando. Algumas vezes, uma única flutuação ou a combinação delas podem tornar-se tão significativas, como resultado de feedback positivo (autocatálise: o próprio resultado da transformação serve de estímulo para nova transformação), que isso abala a organização preexistente. Em determinado momento específico (ponto de bifurcação), é impossível definir previamente qual será a direção da mudança: se o sistema se desintegrará em caos ou saltará para uma estrutura dissipativa: uma nova organização, com nível de ordem maior. É considerada dissipativa porque precisa de mais energia para se sustentar que a estrutura mais simples que ela substituiu. O sistema é levado pelo acaso por uma das soluções possíveis. Uma vez nesse caminho, ele passa a ser regido de forma determinista até outro ponto de bifurcação.

\section{Entropia na Teoria da Informação}

A partir de Boltzmann, em 1877, Claude Shannon desenvolveu uma interpretação estatística que frutificou (FREKEN, 2003). A fórmula tem a notação: $H=-\sum_{i=1}^{n} p_{i} \log p_{i}$ 
Nesse caso, a entropia exprime a quantidade de informação esperada ou a incerteza de uma distribuição de probabilidade. Para Shannon (1948), a comunicação seria constituída por uma sequência de escolhas dentro de um conjunto finito de símbolos elementares. Nela, cada símbolo na sequência da mensagem depende de certas probabilidades, variando de acordo com os símbolos já transmitidos, em um processo estocástico (em que cada passo depende de passos prévios), de tal forma que a entropia, em Shanonn, mede exatamente essa probabilidade do próximo símbolo aparecer na sequência da mensagem. Assim, a entropia seria relativa à variação da incerteza durante a transmissão da mensagem.

Mavrofides, Kameas, Papageorgiou et al. (2011, p. 356), citando outros autores, apresentam que essa incerteza poderia ser chamada surpresa: "se há um conjunto de M símbolos disponíveis e em certo ponto da sequência da mensagem, o símbolo $u$, que tem a probabilidade $\mathrm{P}_{i}$ próxima a zero de acontecer e, eventualmente, isso acontece, o receptor ficará surpreso". Quanto mais surpreendente, maior é o valor da informação. $H$ é sempre positivo, variando de zero ao máximo, quando todos os $\mathrm{P} i$ são iguais (e, portanto, $\mathrm{P} i$ $=1 / n)$, a incerteza é máxima e $H=\log (n)$, tanto maior quanto maior for $n$.

O conceito estatístico da entropia foi apropriado para definir (contar, usualmente via logaritmo) as várias formas de satisfazer determinado conjunto de restrições (FISK, 2011). Freken (2003) aponta que a fórmula estatística da entropia é uma ferramenta útil para indicar a distribuição de elementos de um sistema em momento específico (por exemplo, participação no mercado), para analisar processos que evoluem ao longo do tempo (mudança tecnológica) e para realizar a análise de decomposição. Assim, é utilizada para estudar a concentração industrial, a diversificação corporativa, a diversificação regional da indústria, a concentração de renda e mesmo a teoria organizacional. Com esta capacidade, foi empregada para estudo de sistemas políticos (BYEON, 2005) e para quantificação do declínio dos grandes conglomerados diversificados nos EUA na década de 1980 (DAVIS, DIEKMANN e TINSLEY, 1994).

\section{Metodologia}

Este ensaio, de propósito mais descritivo que explicativo, adotou uma perspectiva positivista sob o primado da objetividade, na expectativa que outros chegarão à mesma conclusão se aceitarem a fundamentação, favorecerem a lógica e seguirem as mesmas etapas. A primeira fase foi investigar como a entropia é apresentada aos estudantes de Administração e contou com dois procedimentos considerados principais e dois subsidiários, em sequência. No primeiro procedimento, foi descartada a priori a possibilidade de entrevista direta com professores que trabalham com o tema. A razão foi evitar constrangimentos futuros devido ao resultado esperado. Por isso, foi aplicado mecanismo alternativo de coleta de dados. Como a TGS é introduzida na disciplina Teoria Geral da Administração (TGA), a estratégia foi identificar alguns livrostexto utilizados na disciplina e fazer um levantamento do que é escrito (e, hipoteticamente, dito pelos professores que adotam tais livros) sobre a entropia. Foram utilizados três critérios cruzados para a seleção da amostra (que pode ser classificada como não estatística, por conveniência) de livros-texto: (i) frequência de ocorrência em bibliografias de ementários divulgados na internet e selecionados nas cinco primeiras páginas para a expressão de pesquisa: <ementa teoria geral administração>, no buscador Google, em 07.02.2013; (ii) reputação do(s) autor(es) e da obra (aferido pelo número de citações no instrumento de busca Google Acadêmico, também em 07.02.2013); e (iii) disponibilidade da obra nos acervos dos autores deste ensaio e nas bibliotecas da Universidade Federal de Minas Gerais (UFMG), do Centro Federal de Educação Tecnológica de Minas Gerais (CEFETMG) e da Universidade Federal de Lavras (UFLA). Foram extraídas as ementas de 42 cursos. A Tabela 1 apresenta os autores, os livros-texto selecionados, sua frequência em ementas e o volume de citações da obra. 
Tabela 1

\section{Livros-texto selecionados}

\begin{tabular}{|l|l|l|l|}
\hline \multicolumn{1}{|c|}{ Autores } & \multicolumn{1}{|c|}{ Livro-texto } & \multicolumn{1}{c|}{ Ementas } & \multicolumn{1}{c|}{ Citaçães } \\
\hline CHIAVENATO, I. & $\begin{array}{l}\text { Introdução teoria geral da } \\
\text { administração }\end{array}$ & 37 & 4.676 \\
\hline MAXIMIANO, A. C. A. & Teoria geral de administração & 20 & 1.289 \\
\hline MAXIMIANO, A. C. A. & Introdução à administração & 9 & 1.465 \\
\hline LACOMBE, F.; HEILBORN, G. & $\begin{array}{l}\text { Administração - princípios e } \\
\text { tendências }\end{array}$ & 5 & 475 \\
\hline MOTTA, F. C. P. & Teoria geral de administração & 6 & - \\
\hline MOTTA, F. C. P.; VASCONCELOS, I. F. & Teoria geral de administração & 5 & - \\
\hline KWASNICKA, E. L. & Introdução à administração & 5 & 357 \\
\hline BERNARDES, C.; MARCONDES, R. C. & Teoria geral da administração & 4 & 60 \\
\hline SILVA, R. O. & Teorias da administração & 3 & - \\
\hline ANDRADE, R. O. B.; AMBONI, N. & Teoria geral da administração & 3 & 64 \\
\hline MORGAN, G. & Imagens da organização & 2 & 2.580 \\
\hline
\end{tabular}

Fonte: dados da pesquisa.

O conteúdo dos livros foi, então, minuciosamente analisado para apurar a conceituação da entropia, caso existisse. No segundo procedimento da fase 1, investigou-se os conceitos relativos à entropia nas fontes dos livros-texto, com o objetivo de inferir a consistência entre as fontes e os livros-texto. Os resultados, que são reportados na seção "Ensino da entropia na Administração, suas fontes primárias e a reação dos alunos", serviram como orientação para dois procedimentos subsidiários. O primeiro tratou da investigação na internet de textos que lidassem de forma mais prática - portanto, textos prescritivos - com a entropia e estivessem em consonância com o compreendido dos livros-texto. Foram pré-selecionados 10 documentos e escolhido um, pelo currículo não confirmado de seu autor, alegadamente, um ex-presidente do Juran Institute. $\mathrm{O}$ Texto 1 é apresentado na nota de rodapé ${ }^{4}$. $\mathrm{O}$ segundo e último procedimento da fase 1 foi a

\footnotetext{
${ }^{4}$ The natural state of things is chaos. This is the principle of entropy: any process, no matter how orderly and well-designed, will degenerate to chaos unless we keep adding energy. And yet, many seemingly bright managers appear shocked to find that the gains so painstakingly achieved have disappeared in only a few short years -- or even months. Every business process requires energy in the form of controls, redesign, new procedures, additional training, performance measurements and many interventions just to maintain its original level of performance. If we want to continuously improve the level of performance, we must add even more energy to the system. There are many reasons why processes degrade over time. Some of these reasons are obvious, others more subtle...Without a good system of measurements and operating system self-controls, we often find out about entropy the hard way. Our wonderful new process starts leading toward chaos (GODFREY, 2014, p. 1).
} 
investigação com graduandos, mestrandos e doutorandos em Administração. Na amostra, também por conveniência, de alunos do CEFETMG e da UFLA, em quatro oportunidades (um dos autores estava ministrando um curso ou aula, com conteúdo distante da entropia, da TGS e da TGA), foi feita entrevista com grupos de 15 a 25 pessoas (total de 72 alunos). O formato foi aberto, a partir da questão: o que vocês conseguem lembrar da Teoria Geral dos Sistemas? As formulações foram apostas em registro ao término das entrevistas, sintetizadas também na "Ensino da entropia na Administração, suas fontes primárias e a reação dos alunos".

Cabe apontar uma objeção a essa construção metodológica: embora os livros-texto estejam disponíveis à análise, a prática pedagógica de cada professor, muito pessoal e de difícil acesso, pode dispensá-los para que outras fontes sejam adotadas, mesmo para explicar a TGS na Administração, até dispensando a conceituação de entropia ou fazendo-a de forma alternativa à identificada nessa investigação. Essa restrição somente é amenizada em parte pela corroboração da segunda fase da pesquisa.

A segunda fase consistiu em buscar pesquisas que adotassem a entropia como ferramenta para o entendimento de fenômenos da Administração. O objetivo foi verificar a operacionalização do conceito. Essa etapa acabou por produzir dois apanhados: (1) trabalhos que lidaram com o caráter termodinâmico da entropia, que aponta para o sentido possível da transformação; e (2) pesquisas que aplicaram a entropia como ferramenta estatística, desprovida de indicação de sentido. Os resultados são apresentados nas duas últimas seções de apresentação dos resultados.

O procedimento inicial da terceira fase foi confrontar ou corroborar as proposições levantadas nas fases anteriores com a estrita aderência à termodinâmica. Obteve-se uma listagem de objeções. $\mathrm{O}$ último procedimento foi correlacionar as evidências com as objeções.

\section{Resultados}

\section{Ensino da entropia na Administração, suas fontes primárias e a reação dos alunos}

Os livros-texto consultados tratam da Teoria dos Sistemas em si, mas nem todos se debruçam sobre o conceito de entropia, como é o caso de Kwasnicka (2006) e Bernardes e Marcondes (2004). Daqueles que o fazem, é possível rastrear as fontes em uma sequência: livro-texto $=>$ Katz e Kahn (em original de 1966) => Bertalanffy (TGS, que pode ser rasteada na conferência em Viena, em 1947) => Prigogine (a partir de 1955), Schrödinger (de 1948) e Boltzmann (de 1877). Cada autor de livro-texto se apropria dos conceitos já secundários ou de terceira ordem e oferece sua interpretação no que tange à entropia nos termos apresentados no quadro 1.

\section{Quadro 1}

\section{Evidência $\{$ En\} de livros-texto}

\begin{tabular}{|c|l|}
\hline En & \multicolumn{1}{|c|}{ Descrição } \\
\hline E1 & $\begin{array}{l}\text { A entropia é uma característica dos sistemas fechados que tem a tendência de se deteriorar e } \\
\text { parar. Os sistemas abertos se sustentam importando energia para compensar as tendências } \\
\text { entrópicas, caracterizando-se por entropia negativa. }\end{array}$ \\
\hline E2 & $\begin{array}{l}\text { A entropia negativa significa que um sistema para sobreviver deve absorver mais energia do que } \\
\text { libera. }\end{array}$ \\
\hline
\end{tabular}


Cont. Quadro 1

\begin{tabular}{|l|l|}
\hline En & \multicolumn{1}{c|}{ Descrição } \\
\hline E3 & $\begin{array}{l}\text { A entropia é a característica de um sistema fechado que indica o seu grau de ordem e desordem. } \\
\text { Para compensar as tendências entrópicas, deve-se importar energia, que é o mesmo que } \\
\text { entropia negativa, capaz de aumentar a ordem. }\end{array}$ \\
\hline E4 & $\begin{array}{l}\text { A entropia é o processo pelo qual todas as formas organizadas tendem à homogeneização e, } \\
\text { finalmente, à morte. A organização pode resistir ao processo entrópico via reposição qualitativa } \\
\text { de energia, mantendo uma relação constante entre importação e exportação de energia, } \\
\text { configurando-se em um estágio estável. A organização cresce mediante aportes adicionais de } \\
\text { energia, alcançando novo estágio em um nível diferente. Adicionalmente, a entropia negativa } \\
\text { levaria as organizações à multiplicação de papéis e à diferenciação interna. }\end{array}$ \\
\hline $\begin{array}{l}\text { A entropia é a própria Termodinâmica: perda de energia em sistema isolado, levando-o à } \\
\text { degradação, à desintegração e ao desaparecimento. Para sobreviver, o sistema precisa abrir-se e } \\
\text { reabastecer-se de energia e de informação, em um processo reativo, denominado entropia } \\
\text { negativa (negentropia). Com o aumento da informação e/ou o reabastecimento reativo de } \\
\text { energia, a entropia seria diminuída. A negentropia é o reverso da Termodinâmica, capaz de } \\
\text { proporcionar integração e organização no sistema e de deter o processo entrópico. }\end{array}$ \\
\hline E6 & $\begin{array}{l}\text { A entropia representa um processo de degeneração: a organização pode perder mais ou menos } \\
\text { energia e essa perda de energia leva à morte a menos que busque outras fontes para se } \\
\text { reabastecer em prol do equilíbrio dinâmico. A entropia negativa é o processo de } \\
\text { reabastecimento, em que a organização lança forças contrárias ao processo de deterioração ou } \\
\text { morte. A entropia positiva decorre quando a organização não consegue se reabastecer. Como as } \\
\text { transformações de um sistema são irreversíveis, a sua entropia aumenta (aumenta-se a } \\
\text { desordem do sistema em direção à máxima desordem). Entretanto, nos sistemas abertos existe } \\
\text { a possibilidade de continuamente importar energia do meio externo e exportar entropia. }\end{array}$ \\
\hline
\end{tabular}

Fonte: $\{E 1\}$ Morgan (2007); \{E2\} Silva (2008); \{E3\} Lacombe e Heilborn (2008); $\{E 4\}$ Motta (1998); Motta e Vasconcelos (2006); \{E5\} Chiavenato (2000); \{E6\} Andrade e Amboni (2009).

Os escritos citados estão bem próximos a Katz e Kahn (1987) - pois deles podem ter sido derivados, em maior ou menor proporção, quer diretamente ou via outro livro-texto. Katz e Kahn (1987) tratam da entropia em cinco oportunidades, listadas como evidência $\{$ E7 $\}$ :

[...] as leis da física newtoniana são corretas, porém limitam-se a sistemas fechados (KATZ e KAHN, 1987, p. 34) [...] à medida que os elementos que o compõem se acomodam em desordem aleatória, a entropia aumenta em direção a um máximo e ocorre o equilíbrio visto que o sistema atinge o estado de distribuição mais provável [...]. Por isso, a operação de entropia é contrariada pela importação de energia e o sistema vivo é caracterizado mais pela entropia negativa que a positiva (KATZ e KAHN, 1987, p. 34). Para sobreviver, os sistemas abertos precisam mover-se para deter o processo entrópico; precisam adquirir entropia negativa. O processo entrópico é uma lei universal da natureza, no qual todas as formas de organização se movem para a desorganização ou morte [...] Entretanto, o sistema aberto, importando mais energia de seu meio ambiente do que a que expende, pode armazená-la e assim adquirir entropia negativa (KATZ e KAHN, 1987, p. 37) [...] Como sistemas abertos, as organizações sobrevivem somente enquanto forem capazes de manter a entropia negativa, isto é, importação de energia, sob todas as formas, em quantidades maiores do que as que devolvem ao ambiente sob a forma de produto [...] Em parte, o input 
de energia é diretamente investido e objetivado como produção organizacional. Porém, uma parte é absorvida e consumida pela organização. Para que haja trabalho de processamento, é preciso que se crie a organização e que esta receba a energia que deverá manter; e isso se reflete na inevitável perda de energia entre o input e o que é produzido (KATZ e KAHN, 1987, p. 169).

Katz e Katz (1987), por sua vez, reconhecem que recepcionaram Bertalanffy, que se propôs ao desenvolvimento da TGS, constituída de princípios básicos interdisciplinares aplicáveis a quaisquer dos fenômenos em consideração - mesmo aqueles com a participação de entidades parcialmente imateriais como valores monetários, boa vontade e outros imponderáveis caros à ciência social (BERTALANFFY, 2012) vindo a se estabelecer como meio para alcançar uma teoria exata nos campos não físicos da ciência, unificando as diversas disciplinas, algo muito necessário, na sua opinião. Ao mesmo tempo, adverte contra os eventuais descuidos na expansão de sua teoria para outros campos além da Biologia e da tecnologia, degenerando-se em analogias sem significado.

Bertalanffy (2012) se contradiz ao afirmar que a termodinâmica declara expressamente que suas leis só se aplicam a sistemas fechados - em um ponto, quanto em outro atesta que, recentemente (na sua época), a físico-química estendeu seus princípios para incluir sistemas abertos. Continuando com Bertalanffy (2012), ele apresenta o Segundo Princípio da Termodinâmica como tendência geral dos acontecimentos na natureza física no sentido dos estados de máxima desordem e do nivelamento das diferenças, com a chamada "morte térmica do universo como perspectiva final, quando toda a energia tiver sido degradada em calor de baixa temperatura uniformemente distribuído" (BERTALANFFY, 2012, p. 66), de tal forma que, em sistemas fechados sujeitos a transformações irreversíveis, a variação de entropia é sempre positiva e a ordem é continuamente destruída. Já em sistemas abertos, teria não somente a produção de entropia devido a processos irreversíveis, mas também a importação de entropia, que poderia ser negativa - citando Prigogine, Schrödinger e Boltzmann. A variação de entropia de um sistema aberto resultaria da adição de uma parcela constituída da produção de entropia devido a processos irreversíveis (sempre positiva) de uma outra parcela, aquela da variação de entropia por importação (negativa quando se importa, por exemplo, matéria como transportadora potencial de energia livre ou entropia negativa). $\{\mathrm{E} 8\}$

Poderia ser dito que os autores de livros-texto analisados e Morgan (2007) apenas apresentaram a TGS, com maior ou menor grau de precisão, de forma acrítica. Isso não procede pois fazem algumas objeções, por exemplo, ao efeito de imponderáveis e determinismo. No primeiro, as organizações seriam dotadas de aspectos materiais (terreno, prédios, máquinas e dinheiro) sob uma construção socialmente construída (visões, normas e crenças) dependentes das ações criativas dos seres humanos, e assim resultariam em sistemas que não seriam funcionalmente unificados como os organismos em homeostase, cujas partes funcionam em harmonia, tal como seres vivos (MORGAN, 2007). No último, alerta-se que teórico pode ser levado à ilusão científica quando aplica instrumentos importados da Biologia adaptados à natureza social dos fenômenos organizacionais (conferindo-lhes determinismo e naturalismo de fenômenos biológicos e termodinâmicos) sem os devidos cuidados (ANDRADE e AMBONI, 2009; MOTTA, 1998; MOTTA e VASCONCELOS, 2006). As consequências de tal conjunto de assertivas podem ter sido determinantes na formulação de duas citações apresentados no final do ensaio $\{\mathrm{E} 9\}$ e $\{\mathrm{E} 10\}$, a título de exemplo.

Já na investigação subsidiária com os estudantes de Administração, o impacto pode ser relativizado, na medida em que foi constatado um pequeno grau de recall imediato da TGS. Quando indagados sobre a TGS foi somente com algum esforço que surgiram os primeiros resultados. As contribuições só aumentaram a partir do momento que alguns alunos supriram as primeiras indicações. A partir daí, houve a concordância, mas não a expansão de dois conceitos mencionados a princípio: desordem e entropia negativa. Tipicamente, restaram duas formulações: (i) as coisas caminham para a desordem devido à entropia; e (ii) para manter a ordem, a organização deve ter (obter, conseguir, usar) entropia negativa. Conceitos como: abordagem de processo, retroação (feedback), homeostasia, equifinalidade e outros da TGS não foram mencionados $\{$ E11\}. 


\section{Entropia como seta do tempo nas pesquisas}

A entropia pode ser apresentada como a seta do tempo (time's arrow), que indica o sentido das transformações, obviamente, irreversíveis. Essa metáfora é creditada a Sir A. S. Eddington (COVENEY e HOGHFIELD, 1990) que, quando a propôs, rememorou Omar Khayyam: "o dedo que se move, escreve; e, tendo escrito, segue: nem toda a sua piedade ou juízo o convencerão a cancelar meia linha, nem todas as suas lágrimas lavarão uma única palavra“" (EDDINGTON, 1928, p. 64).

Como seta do tempo, a entropia não ficou restrita aos livros-texto e às aplicações termodinâmicas em caldeiras. O conceito termodinâmico da entropia foi utilizado em estudos da sustentabilidade de sistemas econômicos de produção, a partir de Georgescu-Roegen (CECHIN e VEIGA, 2010), no questionamento da aderência à rotina (ANAND, GRAY, SIEMSEN et al., 2012), em considerações sobre leis econômicas e mercado (HERSCOVICI, 2005) e na investigação da relação entre padronização e inovação na indústria (JIANG, ZHAO, QIU et al., 2012).

Dados empíricos como os de Anand, Gray e Siemsen (2012) seriam indicativos de que as aderências às rotinas organizacionais decaem com o tempo de forma sistemática e previsível e assim implicaria, na visão daqueles pesquisadores, aumento da desordem, em um processo entrópico (para um estado de entropia mais elevada), em consonância com a termodinâmica - a menos que seja sustida por eventos, como a retroalimentação (eventualmente via auditorias externas do processo) e a cobrança hierárquica, que "adicionam" (entre aspas no original) energia ao sistema para conter, reduzir ou retroagir o avanço do processo entrópico, em um paralelo com sistemas físicos, que também requereriam energia para manter-se em um estado de baixa entropia. $\{$ E12 $\}$

Para Herscovici (2005), a instabilidade estrutural observada em determinados momentos na Economia (em alternância com estados próximos a sistemas conservativos, de produção nula de entropia, esperada pela Lei de Say) se deve à circunstância do mercado criar entropia positiva. \{E13\}

Jiang, Zhao, Qiu et al. (2012) empregaram o princípio do aumento de entropia para estudar o papel da estabilidade dos padrões (normas e especificações) industriais e a volatilidade da inovação em sistemas de padronização. Eles propuseram que fosse admitido como condição inicial um sistema de padronização de baixa entropia, bem organizado e estável. Os padrões já existentes estariam alinhados ao ambiente econômico, ao nível tecnológico e às demandas de mercado. Nesse ponto, as empresas se beneficiam da orientação oferecida pelo padrão. A adoção de um novo padrão não perturbaria o conjunto. Contudo, em algum momento, as interações entre o sistema e o ambiente promoveriam o aumento de entropia que desorganiza o sistema. A tentativa de adotar novo padrão tecnológico decorrente da inovação introduz uma tensão adicional. A entropia continuaria a aumentar, exacerbando a desordem e, assim, levando o sistema à paralisia. As limitações dos padrões em vigor que inibem o processo de inovação ficariam mais evidentes. As empresas perderiam competitividade, os produtos desapareceriam e ficaria mais difícil atender às necessidades dos consumidores. Isso demandaria novos padrões mais avançados e tornaria obrigatório aumentar a capacitação científica, encorajar o emprego de mais conhecimento científico, estimular a inovação, lançar novos padrões, adicionando entropia negativa aos sistemas para contrabalançar a influência adversa da entropia na estabilidade do sistema. Com o acúmulo de entropia negativa, finalmente há uma mudança qualitativa e o sistema atingiria novo equilíbrio, que voltaria a beneficiar as empresas. \{E14\}

Martins (2008) defendeu que as empresas, ao adotar determinadas práticas de gestão (valorização das pessoas, controle financeiro, foco na tecnologia, coordenação administrativa, investimentos - ao longo de todo o seu ciclo de vida; aprendizado e melhoria constantes, conhecimento do mercado, estratégia e metas claras, inovação constante, foco no crescimento e desempenho planejados, estrutura flexível e processo sucessório - em momentos de crise) geram entropia negativa e assim perduram (se tornam longevas). $\mathrm{O}$ argumento é circular: se é necessária a entropia negativa para a sobrevivência das empresas e essas foram as práticas adotadas em empresas longevas, então elas são as responsáveis pela geração de entropia negativa. $\{\mathrm{E} 15\}$ 
Bailey (1990) propõe uma Teoria Social de Entropia, na qual para evitar que a entropia atinja níveis perigosos, uma organização deve, de forma interdependente, assegurar seu espaço físico, amealhar a informação necessária e guardar seus segredos, utilizar a tecnologia apropriada, dividir apropriadamente o trabalho e ajustar-se administrativamente. $\{$ E16 $\}$

\section{Entropia como função de probabilidade em pesquisas}

Se a entropia (S) é expressa da forma: $S=k_{B} \ln \Omega$, então, algo como a entropia negativa seria $-S=k_{B} \ln 1 / \Omega$. Essa expressão foi aproveitada de diversas formas, transcendendo os limites da Física (JIANG, ZHAO, QIU et al., 2012). Primeiro, por Shannon, em 1948, que cunhou o termo entropia da informação, com o sentido de incerteza na disseminação da informação, denotando a habilidade da fonte em enviar uma informação. A notação que foi adotada é $H=-\sum_{i=1}^{n} P_{i} \log P_{i}$, onde $P_{i}$ é a probabilidade de ocorrer o evento, e $H$ é a entropia, uma medida quantitativa da incerteza quando a informação é o equivalente à remoção daquela (MARTÍNEZ-OLVERA, 2008; MATTOS e VEIGA, 2002). A equação de Shannon serviu para avaliar o compartilhamento de informação em cadeias de suprimentos (MARTÍNEZ-OLVERA, 2008). Também tem servido para medir igualdade, espalhamento, similaridade e outros conceitos que surgem em diversas áreas, "ainda que tais conceitos não tenham nenhuma relação direta com alguma noção clássica de entropia" (MATTOS e VEIGA, 2002, p. 40).

\{E17\} A própria PID foi objeto em uma pesquisa que utilizou a equação de Shannon para validar o emprego de outra fórmula para medir o grau de interdisciplinaridade de artigos publicados entre 1975 e 2005 , constantes da base Web of Science. Os resultados das duas equações mostraram-se altamente correlacionados, o que deu maior respaldo às conclusões. Nelas, os pesquisadores apontaram que a interdisciplinaridade caminha em passos mais lentos do que esperado e ainda se deu, na época, com maior frequência em disciplinas próximas (PORTER e RAFOLS, 2009). Cabe reparo que o vocábulo entropy só apareceu uma vez e isso nas referências: a equação de Shannon foi despida de sua origem.

\{E18\} Uma outra aplicação interessante é aquela desenvolvida por Jacquemin e Berry (1979). Eles adaptaram a equação estatística da entropia e a utilizaram como escala para determinar a concentração na indústria e a diversificação em um conglomerado. Para medir a concentração na indústria, os pesquisadores fizeram $E=\sum_{i=1}^{n} P_{i} \ln ^{1} / P_{i}$ onde $P_{i}$ é a fração da empresa $i$ na indústria em estudo. Para medir a diversificação da empresa, utilizou-se a mesma fórmula, fazendo $\mathrm{P}_{i}$ a representação da fração dos negócios da empresa em estudo na indústria $i$. Vale o reparo que $\mathrm{E}$ pode variar de zero, no caso de monopólio (ou para empresa com apenas um tipo de negócio, portanto, sem qualquer diversificação) até, no limite, infinito, para indústria absolutamente fatiada por inúmeras empresas (ou para empresa que participe de inúmeros negócios, sem que nenhum seja significativamente mais importante). A grandeza $E$ foi chamada de Entropia, análoga à entropia da termodinâmica. Seus proponentes testaram-na e concluíram que E, como escala, é superior a outras escalas então existentes. A escala foi bem aceita e assim disseminada, concorrendo com o HerfindahlHirshman Index - HHI nas pesquisas, podendo ser utilizada, por exemplo, em concentração de empréstimos realizados por um banco ou pelo setor bancário, tal como em Laptecru (2012). Uma distinção importante é que nessas aplicações, nada obriga que, para que uma mudança seja possível (exceto no caso limite de $\mathrm{E}=0$ ) a entropia, tal como definida, tenha que aumentar (caminhar no sentido de menor concentração ou maior diversificação). Nesse caso, a entropia não atua como seta do tempo: não se sabe se aumentará ou diminuirá, diferentemente da entropia termodinâmica.

A dimensão estatística da entropia, tratada como técnica para medição da heterogeneidade interna do grupo social, foi utilizada para indicar uma transformação, no caso a transição, para a vida adulta, medindo a mudança de status de adolescentes e jovens. A medida de entropia foi derivada de combinações de status (estudante, trabalhador, chefe de família, cônjuge) por idade específica (VIEIRA, 2008). Aqui foi utilizada a mesma fórmula de Jacquemin e Berry (1979), que Vieira (2008) creditou a H. Theil, de 1972, que teria sido 
o primeiro a utilizar entropia como técnica de decomposição nas ciências sociais. No estudo da transição para a vida adulta, a entropia varia de zero (quando todos os indivíduos em determinada idade estão concentrados em um único estrato, isto é, um tipo de combinação de status) a um máximo, dependente do número total de combinações de status possíveis: a entropia teria seu maior valor na qual se teria a mesma proporção de indivíduos ocupando cada um dos estratos possíveis. A conclusão foi que o ciclo de vida está tornando-se menos previsível, com índices de entropia mais altos. Novamente, não há qualquer menção que isso se deva ao postulado da termodinâmica. $\{$ E19\}

\section{Entropia em manuais de termodinâmica ou daí decorrente}

Se tecem críticas, os autores de livros-texto da amostra endossariam os demais aspectos de Bertallanffy (2012) e Katz e Kahn (1987), inclusive aqueles que são passíveis de contestação. Quando se aplica a termodinâmica, é possível opor quinze objeções ao tratamento conferido à entropia nas evidências listadas, não só de livros-texto, mas também das pesquisas. Antes mesmo de listá-las, há uma questão importante: qual é a hipótese de trabalho de cada autor sobre a distância do equilíbrio do seu objeto de pesquisa (portanto, de seu sistema): no equilíbrio, próximo ao equilíbrio ou distante do equilíbrio? Como foi visto na Fundamentação deste ensaio por Prigogine (1977), isso seria crucial para a aplicação correta da termodinâmica. Verificou-se na amostra que essa declaração é frequentemente omitida e, em troca, apresenta-se uma associação aparente de sistema aberto com sistemas distante do equilíbrio - o que não é suficiente. De pronto, é conveniente ressaltar que na listagem consideraram-se os termos stricto sensu tal qual encontrados na termodinâmica, distante de formulações mais filosóficas e transcendentes como, por exemplo, em Morin (2002). As objeções estão apresentadas no quadro 2.

\section{Quadro 2}

\section{Objeções $\{0 m\}$ da termodinâmica.}

\begin{tabular}{|c|l|}
\hline $\mathbf{0}$ & \multicolumn{1}{c|}{ Descrição } \\
\hline $\mathbf{0 1}$ & $\begin{array}{l}\text { Em Termodinâmica, os sistemas podem ser fechados, isolados ou abertos. O sistema é dito } \\
\text { fechado quando tem massa fixa. É isolado, caso particular de sistema fechado, quando não troca } \\
\text { nem massa nem energia com o ambiente. O sistema aberto é aquele que troca massa e/ou } \\
\text { energia por meio de uma fronteira real ou imaginária. Contudo, o único sistema perfeitamente } \\
\text { isolado é o Universo. Em Termodinâmica, outro sistema isolado é concedido apenas como uma } \\
\text { abstração idealizada a ser escalada na compreensão dos sistemas reais em consideração. É apenas } \\
\text { um estágio de entendimento. A entropia é uma propriedade de qualquer corpo ou elemento, em } \\
\text { um sistema isolado, fechado, isolado ou aberto (SCHMIDT, HENDERSON e WOLGEMUTH et al., } \\
\text { 2004). }\end{array}$ \\
\hline 02 & $\begin{array}{l}\text { Na teoria, um sistema isolado em equilíbrio dinâmico, por exemplo, uma garrafa totalmente } \\
\text { isolada, com metade de seu volume com água e outra metade com vapor de água, que não troca } \\
\text { energia ou matéria com o ambiente (condição inerente do sistema isolado), permaneceria } \\
\text { macroscopicamente tal como está, indefinidamente - sem deteriorar-se ou parar (as moléculas de } \\
\text { água no estado vapor e de líquido, continuariam com a mesma agitação inicial), o que implicaria } \\
\text { variação nula de entropia entre o tempo inicial e qualquer outro momento, não requerendo } \\
\text { importação de energia para tanto. Se houver alguma transformação, a variação de entropia } \\
\text { sempre será nula (processo reversível) ou positiva (ÇENGEL e BOLES, 2011) na ocorrência de } \\
\text { alguma irreversibilidade. }\end{array}$ \\
\hline
\end{tabular}




\begin{tabular}{|c|c|}
\hline 0 & Descrição \\
\hline 03 & $\begin{array}{l}\text { Em condições próximas do equilíbrio, a importação de energia para dentro de um sistema (tão } \\
\text { simples como aquele composto de um gás perfeito) contido por uma fronteira (recipiente fechado } \\
\text { e rígido) implica um aumento das energias cinéticas das moléculas do gás. Níveis energéticos } \\
\text { previamente pouco acessíveis tornam-se agora mais populosos. Isso aumenta a dispersão de } \\
\text { energia por um maior número de níveis energéticos, o que aumenta o número de microestados } \\
\text { do sistema. Se a entropia é definida pela relação: } S=k B l n \Omega \text { (onde } S \text { é entropia, kB é a constante } \\
\text { de Boltzmann e } \Omega \text { é o número de microestados distintos que são compatíveis com o macroestado } \\
\text { do sistema), se } \Omega \text { cresce, } S \text { aumenta. Isso quer dizer que ao se importar energia aumenta-se a } \\
\text { entropia e não o oposto; daí, não há compensação das tendências entrópicas via importação de } \\
\text { energia. O efeito é justamente o oposto do pretendido, pois transferir energia para o sistema } \\
\text { acaba por se constituir em um dos dois modos de aumentar a sua entropia - a outra é fazê-lo } \\
\text { passar por um processo irreversível. Daí, há somente um modo de reduzir a entropia de um } \\
\text { sistema. Este meio é retirar calor (energia) do sistema, transferindo-o ao ambiente (ÇENGEL e } \\
\text { BOLES, 2011; SCHMIDT, HENDERSON e WOLGEMUTH et al., 2004; SONNTAG, BORGNAKKE e } \\
\text { WILEN, 2003). }\end{array}$ \\
\hline 04 & $\begin{array}{l}\text { Pelo terceiro princípio da Termodinâmica, a entropia (absoluta, requerida para análise de reações } \\
\text { químicas) não pode ser negativa (MARTIN, SMITH e FRANCIS, 2013): é, no mínimo, zero, à } \\
\text { temperatura de zero Kelvin, equivalente a menos } 273 \text { graus centigrados, para uma substância } \\
\text { cristalina pura, se dizendo que nessa condição, a estrutura do cristal é tal que apresenta o grau } \\
\text { máximo de ordem - ou melhor, grau mínimo de casualidade - no limite, quando } \Omega \text { é igual a } 1 \text { e } \\
\text { assim } S=0 \text { (SCHMIDT, HENDERSON e WOLGEMUTH et al., 2004; SONNTAG, BORGNAKKE e WILEN, } \\
\text { 2003). Cabe observar que, por algum tempo, aceitou-se a ideia de entropia negativa, uma vez que } \\
\text { a entropia era tomada como zero nas condições padrões de temperatura e pressão, reforçado } \\
\text { pela proposição de Schrödinger (1944) de que os seres vivos precisam alimentar-se de entropia } \\
\text { negativa para não morrer (MARTIN, SMITH e FRANCIS, 2013). Mas quem usa Schrödinger como } \\
\text { referência, também deveria apontar que Schrödinger usa o termo entropia negativa no sentido de } \\
\text { energia livre. Outra explicação, também histórica, relaciona o termo entropia negativa à entropia } \\
\text { na informação: o sinal negativo que Shannon e Schrödinger, antes dele, introduziram na fórmula } \\
\text { de Boltzmann é devido ao fato de o logaritmo de probabilidade (probabilidade sempre igual ou } \\
\text { menor que 1) ser zero ou negativo e as duas fórmulas serem equivalentes: se } S=\mathrm{kBIn} \Omega \text {, então H }= \\
\text { - } S=\mathrm{kBIn} 1 / \Omega \text { (MAVROFIDES, KAMEAS, PAPAGEORGIOU et al., 2011). }\end{array}$ \\
\hline 05 & $\begin{array}{l}\text { Entropia e energia são grandezas tão distintas quanto massa e peso: peso é o produto da massa } \\
\text { pela aceleração e entropia é o quociente entre calor (energia) e temperatura. Apesar de derivados } \\
\text { de outra propriedade, não se deveria (apesar de frequentemente sê-lo) confundi-los. Algo assim, } \\
\text { pode levar a crer que existe alguma coisa tão esdrúxula como entropia elétrica ou entropia } \\
\text { térmica. }\end{array}$ \\
\hline 06 & $\begin{array}{l}\text { A Termodinâmica considera ambiente e sistema em conjunto. Na sua versão mais conhecida, diz- } \\
\text { se que o conjunto (sistema e ambiente) tende à condição de máxima entropia. Portanto, é factível } \\
\text { que o sistema se torne mais organizado, com decréscimo de entropia (unicamente via liberação } \\
\text { de calor ou realizando algum trabalho, compensando, eventualmente com sobra, algum processo } \\
\text { irreversível) e o ambiente menos organizado com aumento de entropia (devido à energia } \\
\text { absorvida, que é igual à liberada pelo sistema), embora o conjunto como um todo se torne menos } \\
\text { organizado, no caso de transformações irreversíveis (SONNTAG, BORGNAKKE e WILEN, 2003). Há } \\
\text { ainda a possibilidade (não é garantido) de o sistema tornar-se organizado como estrutura } \\
\text { dissipativa mesmo recebendo energia do ambiente (daí com aumento de entropia), mas só em } \\
\text { condições distantes do equilíbrio (PRIGOGINE, 1977). }\end{array}$ \\
\hline
\end{tabular}




\begin{tabular}{|c|c|}
\hline 0 & Descrição \\
\hline 07 & $\begin{array}{l}\text { Morgan (2007) concede que a organização é dotada de elementos corpóreos (terreno, materiais, } \\
\text { pessoas, máquinas) e incorpóreos (visões, ideias, normas, crenças e também estruturas), que } \\
\text { coordenam o sistema. A entropia é uma propriedade extensiva (BAILEY, 1997; ÇENGEL e BOLES, } \\
\text { 2011; SONNTAG, BORGNAKKE e WILEN, 2003), portanto, dependente de massa: dois quilos de } \\
\text { qualquer substância têm exatamente o dobro de entropia de um quilo da mesma substância, em } \\
\text { iguais condições termodinâmicas. Elementos incorpóreos, que não têm massa, não têm entropia } \\
\text { (quer positiva quer negativa). Duas organizações, com exatamente os mesmos elementos } \\
\text { materiais, têm a mesma entropia, mesmo que a primeira possua visões, ideias, normas, crenças e } \\
\text { estruturas funcionais e a outra não. O risco de uma ou outra morrer no futuro, devido à } \\
\text { disfuncionalidade, não pode ser inferido pela entropia. Admita uma empresa em que as coisas } \\
\text { não são sistematicamente colocadas em seu lugar apropriado, e outra, muito mais organizada, } \\
\text { mas que tenha sofrido o efeito de um pequeno abalo sísmico. Admita que se encontre as } \\
\text { empresas com exatamente as mesmas coisas distribuídas da mesma forma (uma, por falta de } \\
\text { organização, outra devido ao abalo sísmico). Ambas têm a mesma entropia. Contudo, é razoável } \\
\text { esperar que, passado uma semana, a primeira empresa continue tal como encontrada (em } \\
\text { desordem), enquanto as coisas estariam no seu lugar na outra. Essa expectativa, razoável, não } \\
\text { está alicerçada em quaisquer considerações termodinâmicas. }\end{array}$ \\
\hline 08 & $\begin{array}{l}\text { Fenômenos tipicamente entrópicos como correntes marítimas e dispersão de poluentes não são } \\
\text { disfuncionais, pelo contrário, permitem a vida na Terra. Não há relação entre a funcionalidade e a } \\
\text { redução de entropia. A ferrugem em uma máquina resulta da redução de entropia do sistema } \\
\text { peça + oxigênio circunvizinho (com o aquecimento do ambiente provocando o aumento da } \\
\text { entropia do universo), nem por isso ela é desejável. }\end{array}$ \\
\hline 09 & $\begin{array}{l}\text { Entropia não é boa ou má: somente indica o sentido de uma transformação, física ou química, } \\
\text { possibilitada pelas condições termodinâmicas e assim confere previsibilidade aos fenômenos } \\
\text { (apenas aqueles dotados de massa), pelo menos aqueles mais próximos do equilíbrio, tornando- } \\
\text { os administráveis. Se é o caso de qualificá-la, ela é bem útil como para o pipoqueiro que espera e } \\
\text { que confia, para realizar seu negócio, que o milho vira pipoca e nunca a pipoca irá retroagir ao } \\
\text { estado de milho. }\end{array}$ \\
\hline 010 & $\begin{array}{l}\text { Pelos princípios da conservação de matéria e de energia, toda a matéria e energia que entra na } \\
\text { organização (via trabalho das pessoas, energia elétrica, combustíveis), sai na forma latente de } \\
\text { produtos desejados (aço, pão, energia elétrica) e de outros produtos (poeira, efluentes, emissões } \\
\text { atmosféricas, gases e as próprias pessoas ao final do expediente) e energia (calor, ruído, emissões } \\
\text { ionizantes) inerentes - ou aumentam o estoque de produtos físicos ou o acúmulo de energia. } \\
\text { Importar mais energia (e materiais) do que se exporta somente aumenta o estoque, não gera } \\
\text { nenhuma entropia negativa. Pelo contrário, se aumenta os produtos em estoque dentro da } \\
\text { organização, cada um com a sua entropia própria, aumenta-se a entropia do conjunto. Bailey } \\
\text { (2008) explora esse ponto ao analisar a permeabilidade das fronteiras de arranjos sociais e os } \\
\text { problemas relacionados ao excesso de entradas de materiais e energia. }\end{array}$ \\
\hline 011 & $\begin{array}{l}\text { A Termodinâmica clássica não lida com a exportação de entropia (positiva) e a importação de } \\
\text { entropia negativa, propostas pelo modelo das estruturas dissipativas. Ela não é um dos fluxos } \\
\text { aceitos por Bailey (2008) a atravessar as fronteiras organizacionais. Na verdade, o que se tem é } \\
\text { fluxo de matéria e/ou calor, tal como é aclarado por Prigogine e Stengers (1984), que implica } \\
\text { aumento ou redução de entropia do sistema e do ambiente. }\end{array}$ \\
\hline
\end{tabular}




\begin{tabular}{|c|c|}
\hline 0 & Descrição \\
\hline 012 & $\begin{array}{l}\text { O diamante é uma forma organizada de carbono. E como tal persistirá sem qualquer necessidade } \\
\text { de entropia negativa, conquanto esteja em equilíbrio, pois tais estruturas são "imortais: uma vez } \\
\text { formadas, podem ser isoladas e manter-se indefinidamente, sem ter mais necessidade de } \\
\text { qualquer intercâmbio com o meio" (PRIGOGINE e STENGERS, 1991, p. 10). }\end{array}$ \\
\hline 013 & $\begin{array}{l}\text { Sistemas com iguais elementos macroscópicos, por exemplo estante e livros, têm exatamente a } \\
\text { mesma entropia, quer os livros estejam arrumados ou em desordem: trata-se de erro apresentá- } \\
\text { los como exemplo de variação de entropia. Entropia lida com interações em nível atômico ou } \\
\text { molecular e não com objetos macroscópicos que não interagem entre si (LAMBERT, 1999, p. 1). }\end{array}$ \\
\hline 014 & $\begin{array}{l}\text { Associar entropia à desordem ou mesmo aleatoriedade, é no mínimo controverso - ou totalmente } \\
\text { sem sentido e prejudicial, na visão de Martin, Smith e Francis (2013). De } 2002 \text { a 2006, a definição } \\
\text { que entropia é desordem foi retirada de } 15 \text { das } 16 \text { novas edições de livros-texto adotados por } \\
\text { escolas nos Estados Unidos (LAMBERT, 2006). }\end{array}$ \\
\hline 015 & $\begin{array}{l}\text { Há geração interna de entropia em um sistema quando ocorre uma transformação irreversível, } \\
\text { como por exemplo: atrito, expansão não resistida e redistribuição interna de energia com } \\
\text { diferenças finitas de temperatura, mistura de dois fluidos, resistência elétrica, deformação } \\
\text { inelástica de sólidos e reação química (ÇENGEL e BOLES, 2011). Há geração externa de entropia, } \\
\text { também quando de transformações irreversíveis, como a transferência de calor (SONNTAG, } \\
\text { BORGNAKKE e WILEN, 2003). }\end{array}$ \\
\hline
\end{tabular}

Fonte: dados da pesquisa.

\section{Relação $\{E n\} \&\{O m\}$}

A Tabela 2 oferece uma correlação entre as evidências e as objeções levantadas.

Tabela 2

\section{Relação $\{E n\} \&\{O m\}$}

\begin{tabular}{|c|c|c|c|c|c|c|c|c|c|c|c|c|c|c|c|}
\hline \multirow{2}{*}{ Evidência } & \multicolumn{15}{|c|}{ Objeção } \\
\hline & 01 & 02 & 03 & 04 & 05 & 06 & 07 & 08 & 09 & 010 & 011 & 012 & 013 & 014 & 015 \\
\hline E1 & $x$ & $x$ & $x$ & $\mathbf{x}$ & & & & $x$ & $\mathbf{x}$ & & & & & & \\
\hline E2 & & & & $x$ & & & & & & $x$ & & & & & \\
\hline E3 & $\mathrm{x}$ & & $\mathbf{x}$ & $x$ & $\mathbf{x}$ & & & $x$ & $\mathbf{x}$ & & & & & $x$ & \\
\hline E4 & & & & $\mathbf{x}$ & & & & $x$ & $\mathbf{x}$ & $\mathbf{x}$ & & $\mathbf{x}$ & & & \\
\hline
\end{tabular}




\begin{tabular}{|c|c|c|c|c|c|c|c|c|c|c|c|c|c|c|c|}
\hline \multirow{2}{*}{ Evidência } & \multicolumn{15}{|c|}{ Objeção } \\
\hline & 01 & 02 & 03 & 04 & 05 & 06 & 07 & 08 & 09 & 010 & 011 & 012 & 013 & 014 & 015 \\
\hline E5 & & $x$ & $x$ & $x$ & $x$ & & & $x$ & $x$ & & & & & & \\
\hline E6 & & & & $x$ & & & & $x$ & $x$ & $x$ & & & & $x$ & \\
\hline E7 & $x$ & & $x$ & $x$ & $x$ & $x$ & & & & $x$ & & & & & \\
\hline E8 & $x$ & & & $x$ & $x$ & & & & & & & $\mathbf{x}$ & & $x$ & \\
\hline E9 & & & $x$ & & & & $x$ & $x$ & $x$ & & & $x$ & $x$ & $x$ & \\
\hline E10 & & & $\mathbf{x}$ & & & & & & & $\mathbf{x}$ & & & & $\mathbf{x}$ & \\
\hline E11 & & & $x$ & $x$ & $x$ & & $x$ & $x$ & $x$ & $x$ & & $\mathbf{x}$ & $x$ & $x$ & \\
\hline E12 & & & $x$ & & & & & $x$ & $\mathbf{x}$ & & & & $\mathbf{x}$ & & \\
\hline E13 & & & & & & & $\mathbf{x}$ & & & & & & & & $x$ \\
\hline E14 & $x$ & $x$ & & $x$ & & & & & & & $x$ & & $\mathbf{x}$ & & \\
\hline E15 & & & & $x$ & & & & & & & & & & & \\
\hline E16 & & $x$ & & & & & & & & & & & & & \\
\hline E17 a E19 & & & & & & & & & & & & & & & \\
\hline
\end{tabular}

Fonte: dados da pesquisa.

Na Tabela 2, a confluência da evidência com a objeção é indicada por um $\mathbf{x}$, de tal forma, que, por exemplo, as Objeções $\{\mathrm{O} 1\},\{\mathrm{O} 2\},\{\mathrm{O} 3\},\{\mathrm{O} 4\},\{\mathrm{O} 8\}$ e $\{\mathrm{O} 9\}$ são opostas à Evidência $\{\mathrm{E} 1\}$. As referências das Evidências e das Objeções estão nas seções precedentes deste ensaio. Apenas para a Evidência \{E11\} somou-se as objeções próprias àquelas dos textos que os estudantes tiveram acesso e concordaram com o conteúdo. Se esse critério fosse estendido às outras evidências (sob o argumento de que os autores de livrostexto, mesmo eventualmente não tendo reproduzido uma informação originada de suas fontes e contestada com a Objeção, concordaram com informação, implicitamente, ao não destacar a dissonância), o primeiro terço da Tabela 2 teria ainda mais marcações do tipo x. Pela Tabela 2, as Evidências de $\{$ E1 $\}$ a $\{$ E16\}, que aplicam a entropia como seta do tempo, foram confrontadas com uma ou mais Objeções. Se as objeções são corretas, como os autores acreditam que sejam, o esforço interdisciplinar nesses casos gerou erros e o prejuízo para o ensino. Situação bem distinta para o grupo de evidências de $\{$ E17 $\}$ a $\{$ E19\}, aquelas ligadas 
ao aproveitamento da dimensão estatística da entropia. Para esse grupo, não foram encontrados motivos para Objeção: tanto quanto se sabe, o esforço interdisciplinar apresentou bom resultado. Entretanto, aqui, a entropia é usada como uma escala, não se aplicando à termodinâmica. Isso não retira ou reduz a validade dos achados do grupo, mas a interdisciplinaridade se vê reduzida à aplicação da fórmula gerada na ciência da informação e a ciência em questão.

\section{Conclusão}

Contrariando os textos examinados, a desordem nas organizações não é consequência da termodinâmica, apesar de ela ser aplicável aos elementos corpóreos dessas entidades, mas de maneira divergente, ou mesmo oposta, ao que foi ensinado nos cursos de Administração e ao que foi defendido nos relatos das pesquisas. E não há entropia negativa. Pode-se argumentar que a entropia é utilizada como metáfora em alguns textos e não como grandeza física, com propriedades definidas e regidas por lei fundamental. Isso, eventualmente, seria aceitável, mas pouco interessante, se ela não estiver associada à Segunda Lei da Termodinâmica. Prover a metáfora de determinismo (as coisas serão assim devido à lei natural) é incabível se a metáfora estiver desprovida de qualquer uma de suas propriedades (BAILEY, 2001).

Uma explicação para o uso inadequado do conceito de entropia pode estar ligada ao fato de que uma série de constatações verdadeiras e uma falsa pode produzir uma síntese equivocada, mas bem atraente pela simplicidade. Assim: (1) nas organizações, é fato a propensão à deterioração: os processos tendem a ser descumpridos ou mesmo ser ultrapassados, as máquinas se desgastam e quebram, os materiais são gradativamente degradados e as pessoas perdem a motivação; (2) existe uma lei da termodinâmica que indica que, havendo alguma transformação, tal como acima, ela somente seria possível se produzisse um aumento de entropia, no universo; (3) o aumento da entropia indica a mudança de ordem para a desordem; e (4) a organização recorre ao trabalho (quer de controle, quer mesmo mecânico) para manter-se em um estado de ordem, requerido ao seu funcionamento.

Daí, as coisas deixam de funcionar porque caminham para a desordem devido à entropia, que deve ser combatida, por meio do trabalho que é, portanto, o inverso da entropia (o negativo da entropia, ou entropia negativa). Aplica-se aqui uma frase atribuída ao filósofo George Bernard Shaw: "para todo problema complexo, existe uma solução clara, simples e errada" (BULCÃO NETO, 2006, p.38). Se, como argumentado, a entropia (termodinâmica) não se aplica a elementos incorpóreos da organização e não guarda relação com a aparente desordem de elementos macroscópicos (entre outras objeções), a síntese produzida pelo esforço interdisciplinar é falha, mesmo que consagrada e aparentemente simples e lógica.

A consequência é o descarte prematuro de outras explicações alternativas. Por exemplo, de ordem antropológica ou estatística. É mais natural jogar as coisas para qualquer lado do que se esforçar para leválas ao lixo. Ou as coisas não ficam em ordem, porque existem muitas formas de dispô-las. Aquela considerada mais funcional (em ordem) é apenas uma dentre uma multiplicidade de opções. Se a probabilidade é a mesma de um evento ordem e de cada um dos $u$ eventos não ordem, e há uma sequência $v$ de transformações, só por muita sorte prevalecerá a ordem, tanto maior quanto forem $u$ e $v+1$.

Outra questão em relação a essas explicações é: por que, novamente, sendo válido o que até aqui foi apresentado, o erro é reproduzido em novas pesquisas que conseguem aval científico pela publicação em periódico. Uma hipótese seria que os periódicos brasileiros de Administração não contam com revisores interdisciplinares, habilitados em termodinâmica, capazes de apontar tais objeções. O teste dessa suposição extrapola os limites da pesquisa.

De tudo exposto, considera-se razoável concluir que:(i) ressalvando os efeitos potenciais positivos da interdisciplinaridade (no caso, aplicação da fórmula da ciência da informação em outros áreas) ela pode amplificar a possibilidade de se gerar erros; (ii) a Administração tem tratado o conceito termodinâmico da 
entropia de forma inapropriada; (iii) os autores de livros-texto deveriam posicionar-se diante dos questionamentos oferecidos na Tabela 3; e (iv) os periódicos podem não ser adequados para lidar com trabalhos interdisciplinares.

Cabe uma ressalva: pelo menos um livro de termodinâmicos aceitou uma extensão da entropia para fora de seu stricto sensu. Esse exemplo está em Çengel e Boles (2011). O Texto ${ }^{5}$ 2, apresenta o que eles atestaram em uma extensão consideravelmente conflitante ao que foi aceito pelos autores deste ensaio.

Finalmente, não se condena a interdisciplinaridade: somente a relativiza, colocando-a como sujeita a riscos, que merecem cuidados especiais - inclusive, desta própria pesquisa.

\section{Referências}

ABOELELA, S. W. et al. Defining interdisciplinary research: conclusions from a critical review of the literature. Health Services Research, v. 42, n. 1, p. 329-346, 2007.

ABONI, N. et al. Interdisciplinaridade e complexidade no curso de graduação em administração. Cad. EBAPE.BR, v. 10, n. 2, p. 302-328, 2012.

ANAND, G.; GRAY, J.; SIEMSEN, E. Decay, shock, and renewal: operational routines and process entropy. Organization Science, v. 23, n. 6, p. 1700-1716, 2012.

ANDRADE, R. O. B.; AMBONI, N. Teoria geral da administração. Rio de Janeiro: Elsevier, 2009.

BAILEY, K. D. Social entropy theory. Systems Practice, v. 3, n. 4, p. 365-382, 1990.

BAILEY, K. D. System entropy analysis. Kybernetes, v. 26, n. 6/7, p. 674-688, 1997.

BAILEY, K. D. Towards unifying science. Systems Research and Behavioral Science, v. 18, p. 41-62, 2001.

BAILEY, K. D. Boundary maintenance in living systems theory and social entropy theory. Systems Research and Behavioral Science, v. 25, n. 5, p. 587-597, 2008.

BARRY, A.; BORN, G.; WESZKALNYS, G. Logics of interdisciplinarity. Economy and Society, v. 37, n. 1, p. 20-49, 2008 .

BENGUIGUI, L. The different paths to entropy. European Journal Physics, v. 34, p. 303-321, 2013.

BERNARDES, C.; MARCONDES, R. C. Teoria geral da administração: gerenciando organizações. 3. ed. São Paulo: Atlas, 2004.

BERTALANFFY, L. V. Teoria geral dos sistemas. 6. ed. Petrópolis, RJ: Vozes, 2012.

5 Pessoas eficientes levam uma vida de baixa entropia (altamente organizada) e gastam o mínimo de energia para localizar alguma coisa; e aquelas que levam uma vida de alta entropia estão sempre correndo e nunca parecem chegar ao ponto. Pessoas que aprendem rápido e se lembram com facilidade é porque aprendem de forma organizada, de baixa entropia, fazendo um esforço consciente de arquivar devidamente a nova informação na sua base de conhecimento já existente. Uma biblioteca com um eficiente sistema de indexação pode ser vista como uma biblioteca de baixa entropia. [...] Como atrito leva à geração de entropia, isso pode ser generalizado: atrito de trabalhadores em empresas geram entropia e daí reduzem a produtividade. Como uma expansão irrestrita e uma reação química geram alta entropia por serem altamente irreversíveis, abrir a boca para proferir palavras raivosas é altamente irreversível, gera entropia e assim provoca danos (ÇENGEL e BOLES, 2011, p. 321). 
BORREGO, M.; NEWSWANDER, L. K. Definitions of interdisciplinary research. The Review of Higher Education, v. 34, n. 1, p. 61-84, 2010.

BULCÃO NETO, M. S. Sombras do Iluminismo. Rio de Janeiro: 7 Letras, 2006.

BYEON, J. H. A systems approach to entropy change in political systems. Systems Research and Behavioral Science, n. 22, p. 223-231, 2005.

CECHIN, A. D.; VEIGA, J. E. A economia ecológica e evolucionária de Georgescu-Roegen. Revista de Economia Política, v. 20, n. 3, p. 438-454, 2010.

ÇENGEL, Y. A.; BOLES, M. A. Thermodynamics. 6. ed. New York: McGraw-Hill, 2011.

CHIAVENATO, I. Introdução à teoria geral da administração. Rio de Janeiro: Campus, 2010.

CORNING, P. A.; KLINE, S. J. Thermodynamics, information and life revisited, part 1: to be or entropy. Systems Research and Behavioral Science, n. 15, p. 273-295, 1998.

COVENEY, P.; HOGHFIELD, R. The arrow of time. London: Flamingo, 1990.

DAVIS, G. F.; DIEKMANN, K. A.; TINSLEY, C. H. The decline and fall of the conglomerate firm in the 1980s. American Sociological Review, n. 59, p. 547-570, 1994.

EDDINGTON, A. S. The nature of the physical world. London: MacMillan, 1928.

FISK, D. Thermodynamics on Main Street. Ecological Economics, n. 70, p. 1931-1936, 2011.

FREKEN, K. Entropy and information theory. In: HAMUSCH, H.; PYKA, A. (Eds.). The Elgar companion to neoSchumpeterian economics. Cheltenham: Edward Elgar, 2003.

GODFREY, A. B. Entropy. Disponível em: 〈http://www.qualitydigest.com/june97>. Acesso em: jan. 2014.

HERSCOVICI, A. Historicidade, entropia e não linearidade: algumas aplicações possíveis na ciência econômica. Revista de Economia Política, v. 25, n. 3, p. 277-294, 2005.

HUUTONIEMI, K. et al. Analyzing interdisciplinarity: typology and indicators. Research Policy, v. 39, n. 1, p. 79-88, 2010 .

JACOBS, J. A.; FRICKEL, S. Interdisciplinarity: a critical assessment. Annual Review of Sociology, n. 35, p. 43-65, 2009.

JACQUEMIN, A. P.; BERRY, C. H. Entropy measure of diversification and corporate growth. The Journal of Industrial Economics, v. 27, n. 4, p. 359-369, 1979.

JIANG, H. et al. Strategy for technology standardization based on the theory of entropy. Information Technology and Management, v. 13, n. 4, p. 311-320, 2012.

KATZ, D.; KAHN, R. Psicologia social das organizações. 3. ed. São Paulo: Atlas, 1987.

KLEIN, J. T. Evaluation of interdisciplinary and transdisciplinary research: a literature review. American Journal of Preventine Medicine, v. 35, n. 2S, p. 116-123, 2008.

KWASNICKA, E. L. Introdução à administração. 6. ed. São Paulo: Atlas, 2006.

LACOMBE, F.; HEILBORN, G. Administração. 2. ed. São Paulo: Saraiva, 2008. 
LAMBERT, F. L. Shuffled cards, messy desks, and disorderly dorm rooms: examples of entropy increase? Nonsense! Journal of Chemical Education, n. 76, p. 1385-1387, 1999.

LAMBERT, F. L. A modern view of entropy. Chemistry, v. 15, n. 1, p. 13-21, 2006.

LAPTECRU, I. Assessing lending market concentration in Bulgaria. The European Journal of Comparative Economics, v. 9, n. 1, p. 79-102, 2012.

MARTIN, J. S.; SMITH, N. A.; FRANCIS, C. Removing the entropy from the definition of entropy. Evolution: Education and Outreach, v. 6, n. 30, p. 2-9, 2013.

MARTÍNEZ-OLVERA, C. Entropy as an assessment tool of supply chain information sharing. European Journal of Operational Research, n. 185, p. 405-417, 2008.

MARTINS, G. J. T. Os desafios da gestão rumo à longevidade organizacional: estudo em três organizações do setor têxtil de Santa Catarina. 245f. Dissertação (Mestrado em Administração) - Universidade Federal de Santa Catarina, Florianópolis, 2008.

MATTOS, R. S.; VEIGA, A. Otimização de entropia: implementação computacional dos princípios Maxent e Minxent. Pesquisa Operacional, v. 22, n. 1, p. 37-59. 2002.

MAVROFIDES, T. et al. On the entropy of social systems. Systems Research and Behavioral Science, v. 28, n. 4, p. 353-368, 2011.

MORGAN, G. Imagens da organização. São Paulo: Atlas, 2007.

MORILlO, F.; BORDONS, M.; GÓMEZ, I. Interdisciplinarity in science. Journal of the American Society for Information Science and Technology, v. 54, n. 13, p. 1237-1249, 2003.

MORIN, E. O método 1: a natureza da natureza. Porto Alegre: Sulina, 2002.

MOTTA, F. C. P. Teoria geral de administração. 22. ed. São Paulo: Pioneira, 1998.

MOTTA, F. C. P.; VASCONCELOS, I. F. G. Teoria geral da administração. 3. ed. São Paulo: Cengage Learning, 2006.

NATIONAL ACADEMY OF SCIENCES. Facilitating interdisciplinary research. Washington, DC: National Academy Press, 2005.

NOVAES, M. Ilya Prigogine: uma visão crítica. Revista Brasileira de Ensino da Física, v. 22, n. 1, p. 1306.1-1306.4, 2010.

PERZ, S. G. et al. Crossing boundaries for environmental science and management. Environmental Conservation, v. 37, n. 4, p. 419-431, 2010.

PORTER, A. L.; RAFOLS, I. Is science becoming more interdisciplinary? Measuring and mapping six research fields over time. Scientometrics, n. 3, p. 719-745, 2009.

PRIGOGINE, I. Time, structure and fluctuations. [S.1]: Nobel Lecture, 1977.

PRIGOGINE, I.; STENGERS, I. Order out of chaos. London: Flamingo, 1984.

PRIGOGINE, I.; STENGERS, I. A nova aliança. Brasília, DF: UnB, 1991.

RIJNSOEVER, F. J. V.; HESSELS, L. K. Factors associated with disciplinary and interdisciplinary research collaboration. Research Policy, v. 40, p. 463-472, 2011. 
SÃo PAUlo (Estado). Currículo do Estado de São Paulo: Ciências da Natureza e suas tecnologias. São Paulo: Secretaria da Educação, 2010.

SCHMIDT, F. W.; HENDERSON, R. E.; WOLGEMUTH, C. H. Introdução às ciências térmicas. São Paulo: Edgard Blücher, 2004.

SCHRÖDINGER, E. What is life? Cambridge: Cambridge University, 1944.

SHANNON, C. E. A mathematical theory of communication. The Bell System Technical Journal, n. 27, p. 379-423, 1948.

SILVA, R. O. Teorias da administração. São Paulo: Pearson Prentice Hall, 2008.

SONNTAG, R. E.; BORGNAKKE, C.; WILEN, G. J. V. Fundamentos da termodinâmica. 6. ed. São Paulo: Edgard Blücher, 2003.

VIEIRA, J. M. Transição para a vida adulta no Brasil: análise comparada entre 1970 e 2000 . Revista Brasil de Estudos Populacionais, v. 25, n. 1, p. 27-48, 2008. 